\title{
Mark Rothko, No. 5/No. 22
}

\section{Andrea Pappas}

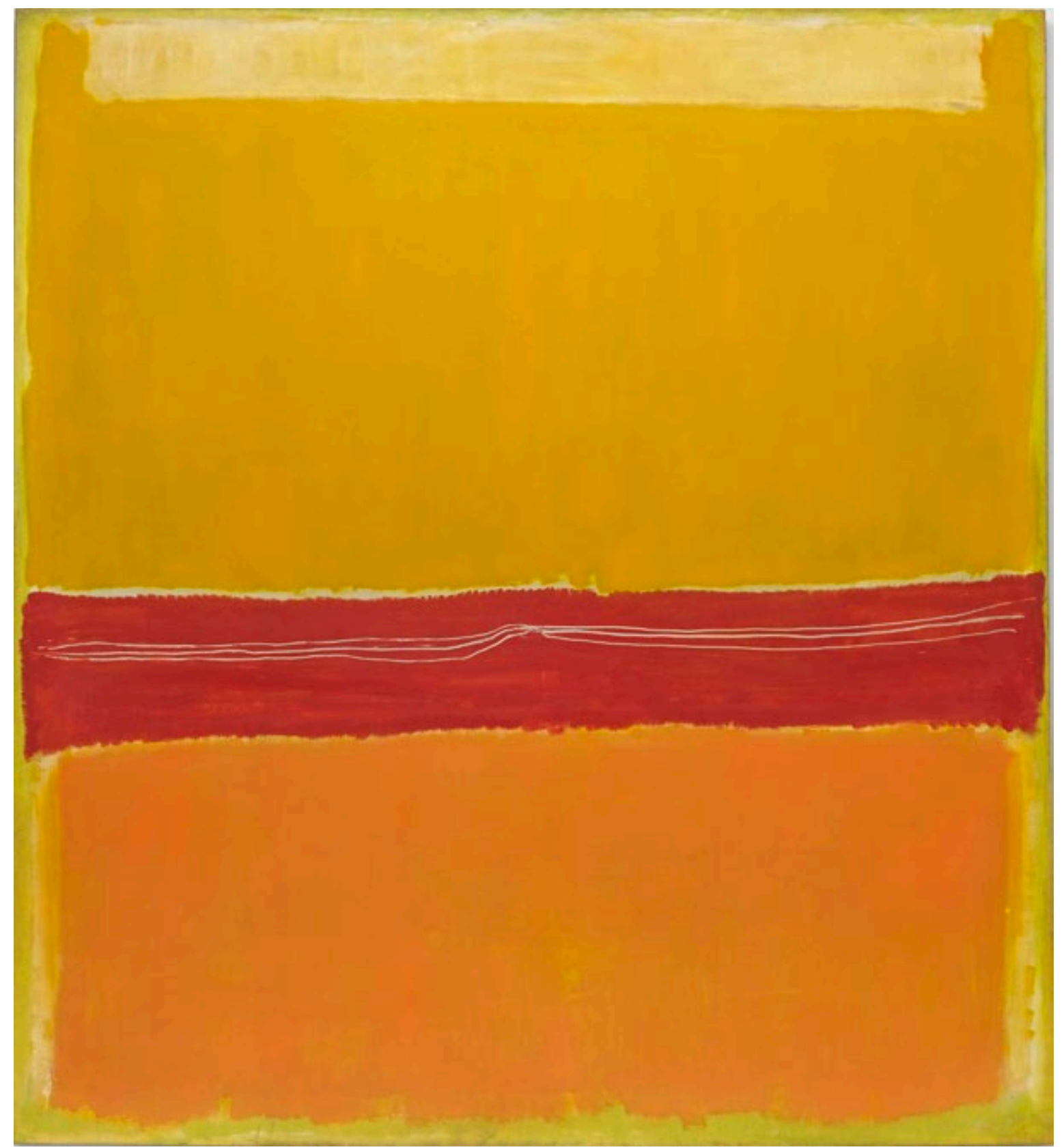

Mark Rothko, No. 5/No. 22, 1950 (dated on reverse 1949).

Strong, gestural markings in the central red band distinguish this painting from Rothko's other mature works. This anomaly consists of long, gently undulating lines formed by gouging the surface of the paint all the way to the canvas before it dried. Straining out from a central point, the horizontal lines contrast sharply with the fuzzy, indeterminate edges of the other elements of the painting. Formed by scraping repeatedly through the paint with the edge of something about a half-inch wide, perhaps 
the blunt end of a palette knife, Rothko labored at the placement and curvature of these elements; close examination reveals that he over-painted and re-scored them several times. Knotted and kinked at the center, the three contours on each side stretch out almost to the edges of the red field to which they are bound. On the right hand side the ends bunch together; on the left they spread like fingers. Such careful working indicates that the form and placement of them was a matter of great concern to him. It was not just the location of the lines that was important-some reworking nearly duplicates earlier placements and curvatures-but also their gestural quality.

Such gestural characteristics recall a specific feature of his earlier work: in 1940-41, Rothko produced a few paintings and several works on paper featuring images explicitly referencing the Crucifixion. These works, although often semi-surrealistic and composed of fragmented bodies, typically include a familiar depiction of human suffering: two or more arms nailed through the hands to a narrow form resembling piece of timber. ${ }^{1}$ Sometimes a work's only explicit reference to the Crucifixion, the image is enough to invoke this subject matter unambiguously for most Western viewers. This particular image of the outstretched, fastened down arms seems to have been particularly compelling for Rothko; indeed, it is the central image in the drawing most closely related to his landmark painting Antigone of $1941 .^{2}$ The elongated, gestural scrapings in the narrow red block in No. 5/No. 22 echo, however abstractly, those earlier Crucifixionrelated images of the Jesus' arms nailed to the timber of the cross.

Why would a Jewish artist make images of the Crucifixion, abstracted or otherwise? I have argued elsewhere that Rothko both engaged the iconography of the "Jewish Jesus"- used by other artists to protest the treatment of Jews at the hands of their persecutors during World War II, as well as distanced himself from it, to fashion an identity as an "American," modern artist. ${ }^{3}$ It was not an accident that these Crucifixion images turned up in the early 1940s; but the possible prompting for this image in $1949 / 1950$ is not so obvious. Rothko said about this painting that he thought it was "rather violent." 4 The easiest place to see violence is in those evocatively extended cuts in the body of the red pigment. But Rothko-whose work in the previous decade frequently fixated on violence, sacrifice, burial, and possible redemption-undoubtedly referred to more than just his working process with this remark. At the end of the 1940s the fate of Jewry again figured prominently on the world stage. Perhaps it was the non-stop series of wars that the new state of Israel was embroiled in almost from the moment of its founding that prompted both the cutting into the painted surface and his comment.

Mark Rothko's “classic" works have frequently been interpreted in spiritual, if not religious terms. The paintings invoke such a response via the format and particularly, the semi-diaphanous surfaces and soft, indistinct edges of the forms, the indeterminacy of which can produce a kind of altered state in the viewer. This painting functions that way also. But by anchoring it in a specific, traceable gesture, the artist reminds us that pain and suffering remain part of life even as we are transported by the ethereal aura created by the rest of the composition.

(C) Andrea Pappas 


\section{Citation Guide}

1. Andrea Pappas, "Mark Rothko, No. 5/No. 22," Object Narrative, in Conversations: An Online Journal of the Center for the Study of Material and Visual Cultures of Religion (2014), doi:10.22332/con.obj.2014.43

Pappas, Andrea. "Mark Rothko, No. 5/No. 22." Object Narrative. In Conversations: An Online Journal of the Center for the Study of Material and Visual Cultures of Religion (2014). doi:10.22332/con.obj.2014.43

\section{Notes}

1. E.g., Crucifix, 1941/1942, Untitled, 1941/1942, Untitled, 1941/1942 (numbers 187, 190, 191 in the Rothko Catalogue Raisonne, Mark Rothko, Works on Canvas.) See perma.cc/otfu1a7SLkY,

2. In Antigone and other paintings, the board-like form with its pinned arms as it appears in the drawings is transformed into a rectangular, sarcophagus-like box containing jumbled body parts or semi-abstract figural decorations.

3. Andrea Pappas, "Invisible Points of Departure: Reading Rothko's Christological Imagery," Journal of American Jewish History 92, no. 4 (December 2004): 401-436. doi:10.1353/ajh.2007.0011

4. John Elderfield comment at perma.cc/oN1Jg6J2AhS See "Other Texts" tab. 